\title{
Industrial Applications of Superhydrophobic Coatings: Challenges and Prospects
}

\section{Süperhidrofob Yüzeylerin Endüstriyel Uygulamaları: Sorunlar ve İmkanlar}

\author{
Hüsnü Yıldırım Erbil \\ Department of Chemical Engineering, Gebze Technical University, Gebze, Kocaeli, Turkey.
}

ABSTRACT

The use of the superhydrophobic coatings and materials in industry is not satisfactory after the intensive activity in research laboratories in the last two decades. We discussed the reasons for this adverse situation under several topics in this review article. The most important issues are the insufficient mechanical resistance and inevitable contamination of the SH surfaces under outdoor conditions, resulting in short useful life-time. The fabrication of a SH surface requires a rough structure with tiny textures on it and this frail framework has a poor mechanical resistance. The topics of superfluous production of small scale and expensive SH surfaces, the difficulty to obtain transparent and also self-healing SH surfaces, the inefficient anti-icing applications of the $\mathrm{SH}$ coatings are also discussed.

\section{Key Words}

Superhydrophobic, coatings, water-repellent, industrial applications.

\section{öz}

üperhidrofob yüzeylerin endüstrideki kullanımı, son 20 senedir araştırma laboratuvarlarında yapılan yoğun çalışmalara $\checkmark$ rağmen tatmin edici bir seviyede değildir. Bu derleme makalesinde, bu negatif durumun sebepleri bazı alt başlıklar altında tartışılmıştır. En önemli sorunlar, SH yüzeylerin mekanik dayanımlarının zayıf olması ve açık hava koşullarında meydana gelen kaçınılmaz kontaminasyonun bunların kullanım süresini kısaltmasıdır. SH yüzeylerin eldesi için zayıf ve ince yapıların yüzeyde olmasına ihtiyaç vardır ve bu durum da bu yüzeylerin mekanik dayanımını azaltmaktadır. Tartışılan diğer sorunlar, gereksiz yere laboratuvarlarda yapılan ve ancak küçük alan kaplayabilen pahalı sentezler, şeffaf ve kendini onaran SH yüzey elde edilmesindeki sorunlar ve SH yüzeylerin buzu itme çalışmalarındaki başarısızlığıdır.

\section{Anahtar Kelimeler}

Süperhidrofob, kaplama, su itici, endüstriyel uygulama.

Article History: Received: Aug 27, 2020; Revised: Sep 20, 2020; Accepted: Oct 20, 2020; Available Online: Oct 20, 2020. DOI: https://doi.org/10.15671/hjbc.810490

Correspondence to: H.Y. Erbil, Department of Chemical Engineering, Gebze Technical University, Gebze, Kocaeli, Turkey. E-Mail: yerbil@gtu.edu.tr 


\section{INTRODUCTION}

"hydrophilic" surface is defined as the surface having a water contact angle $(\theta)$ smaller than $90^{\circ}$ on it, and a "hydrophobic" surface where $\theta$ larger than or equal to $90^{\circ}$. A "superhydrophobic" (SH) surface is defined having water $\theta^{\prime}$ s larger than $150^{\circ}$ with a roll-off angle (inclination angle) of less than $10^{\circ}$ at ambient conditions [1-7]. In nature, a lotus leaf pushes back the dirt and mud because of its $\mathrm{SH}$ characteristics and it was found that its water-repellent properties were due to specific two size range roughness on the leaf's surface $[8,9]$. There are micrometer scale papillae having 5 to 9 $\mu \mathrm{m}$ diameters and also nano-sized protrusions with average diameters of $124 \pm 3 \mathrm{~nm}$ on the lotus leaf. The term "lotus effect" is used to describe SH behavior of such natural and synthetic surfaces. It was determined that low surface free energy is provided by the epicuticula wax covered these papillae and a large extent of air pocket trapping occurs when this two size ranged structure is contacted with water droplets [8,9]. Later, some researchers reported that butterfly and cicada wings, gecko feet, mosquito and moth eyes, rice leaves and red rose petals exhibit superhydrophobic characteristics [10-13].

The synthesis of SH surfaces in the laboratory scale was successfully carried out using two main routes after 1990's. The first one is introduction of the micro and nano- scale roughness onto hydrophobic substances having low surface free energy, and the second one is the modification of a former micro/nano-structured rough surface by coating with a hydrophobic layer having low surface free energy [5-7]. Many good review articles were appeared in the literature on the synthesis, applications and characterization of the SH surfaces [57,13-25].

Various potential applications were proposed for the $\mathrm{SH}$ surfaces in industry, such as self-cleaning exterior paints, transparent windows, mirrors, windshield glass; transparent coatings for panels in solar energy industry; stain and water resistant clothing in textile industry; surveillance cameras, lenses and telescopes in optical industry; icephobic coatings in aerospace and wind turbine industry; corrosion protection coating in metal and pipeline industry and anti-biofouling paints in marine industry [13-25]. SH surfaces were also used in the biomedical field ranging from blood vessel replacement to wound management [14]. Electrowetting is a new technological field where some $\mathrm{SH}$ surfaces can switch between the hydrophobic and hydrophilic states or change its hydrophobic/philic properties under the influence of electric potential [26]. Wetting control on surfaces is an important field where many functional and restructured surfaces were synthesized and characterized $[27,28]$.

On the other hand, the use of the SH coatings and materials in industry is not satisfactory after the intensive activity in research laboratories in the last two decades. There are various reasons for this adverse outcome. The main problem is that $\mathrm{SH}$ surfaces lose their water repellent properties easily when they are exposed to outdoor conditions. The fabrication of a SH surface requires a rough structure with tiny textures on it and this frail framework has a poor mechanical (abrasion) resistance [29]. It is possible that the application of small mechanical forces can destruct the surface texture made of many tiny structures and lead to the loss of the $\mathrm{SH}$ properties. Afterwards, any water droplet cannot roll off on this SH surface, but stick to the damaged locations. The other important problem is the contamination of SH surfaces in open conditions. Dust, other particulate matter, volatile organic compounds (VOC) or surface-active materials can be adsorbed on a SH surface in a short time causing an increase in the surface free energy of the surface. Moreover, the air pockets which are previously present on the $\mathrm{SH}$ surface will be also lost and their absence finishes the initial SH properties of the surface [7].

We will focus on the scientific and technical reasons preventing the extensive industrial applications of the $\mathrm{SH}$ materials and coatings in industry in this review article. In general, the employment of very expensive small scale fabrication methods in laboratories which are not suitable for large scale production; the lack of sufficient robustness and durability of most of the SH surfaces; and the removal of SH properties due to contamination in open conditions are the most important negative technical reasons. On the other hand, the synthesis of transparent SH surfaces are difficult due to the presence of surface roughness, which disperse the incoming light. Similarly, most of the SH surfaces performed inadequately in anti-icing and also in selfhealing applications for a number of reasons. Besides, there is a lack of appropriate standard test methods to determine the abrasion resistance on the SH surfaces. All of these issues will be discussed in this review article. 


\section{Superfluous Production of Small Scale and Expensive SH Surfaces}

Many different approaches were used to obtain $\mathrm{SH}$ surfaces, including phase separation, sol-gel processing, in-situ polymerization, polymer spraying, wax solidification, lithography, templating, hydrophobization by vapor deposition, surface fluorination, synthesis of polymer/particle hybrid coatings including silica, and other inorganic or organic particles, electrospinning, electrochemical methods on metal substrates, hydrothermal synthesis, layer-by-layer deposition etc. [5,1324]. However, most of these SH preparation methods can be applied to produce only very small SH areas or onto some specific materials by the employment of tedious multistep approaches under harsh conditions, or require the use of specialized instruments and expensive chemicals. For example, when deep reactive ion etching (DRIE) technique is used to obtain a patterned surface on a small area of a low surface energy material, the production cost is very expensive and it is very difficult to utilize the same method for large areas [30]. In general, most of the methods reported in articles existing in the literature cannot be used to obtain large-scale and low cost SH surfaces [13-24]. Unfortunately, only very few articles in the SH surface field put emphasis on the industrial applications and the durability issues.

Another problem is the use of fluorine atom containing compounds as monomers or hydrophobization agents during the synthesis of SH surfaces. Fluorine containing compounds are generally expensive and environmentally harmful. In reality, there is no requirement to use them in the production of $\mathrm{SH}$ surfaces if we remember that a water contact angle of $160^{\circ}$ can be achieved on a lotus plant with a very small tilt angle by the presence of paraffinic wax crystals comprising only the $-\mathrm{CH}_{2}-$ and $-\mathrm{CH}_{3}$ groups. This indicates that the synthesis of a hydrophobic surface having both micro- and nanometer length scales is the most important factor and there is no requirement to use fluorine chemicals to accomplish the SH properties. In summary, the use of high-cost materials and harmful chemicals is not suitable for largescale SH surface production. On the contrary, the use of low cost chemicals by applying a single-step fabrication method should be the objective to utilize the SH surfaces in industry.

\section{Insufficient Mechanical Resistance of SH Surfaces}

Surface structures containing micrometer sized needlelike or pillar-like forms are assumed to be ideal surfaces for the formation of a very high water contact angles on a $\mathrm{SH}$ surface, but these structures have very poor mechanical resistance. If nanoscale textures are also present on a two-size range $\mathrm{SH}$ materials, very small mechanical forces can easily destruct the surface texture and lead to the local loss of the SH properties [31,32]. Water droplets cannot roll off on such a damaged $\mathrm{SH}$ surface, but stick to the destroyed locations resulting in an irreversible decrease of water $\theta$ and increase of contact angle hysteresis on such places. Furthermore, the dirt removal from between the protrusions on a $\mathrm{SH}$ surface by rubbing mechanically becomes difficult after the self-cleaning effect lost. The mechanical weakness of $\mathrm{SH}$ surfaces is one of the most important problem preventing their application in industry. On the contrary, the formation of roughly hemispherical protrusions and crater-like structures on a surface is suitable to impart mechanical resistance to the $\mathrm{SH}$ surfaces however, only low water $\theta$ can be obtained on such surfaces. Since the mechanical resistance of a $\mathrm{SH}$ surface is a very important property, it is expected that the most of the authors reported this issue for the newly synthesized $\mathrm{SH}$ surfaces in the articles, but this is not the case and was justifiably criticized in some articles [20,32].

The mechanical durability of a SH surface can be assessed by measuring the resisting tangential abrasive forces, the adhesion forces to the substrate and the forces to prevent the damage of dynamic impact $[20,21]$. "Tape peel test" is usually applied to measure the adhesive ability of a SH surface to a substrate. For this test, an adhesive tape is pressed onto the $\mathrm{SH}$ test surface to eliminate the air entrapment and to ensure uniform adhesive contact and then, the tape is stripped off from one end vertically. Afterwards, the surface of the coating is examined whether the coating is totally or partially removed. Later, water $\theta$ is measured again to check whether its value is still larger than $150^{\circ}$. The conventional "cross-cut test" which is a popular test in surface coatings industry is sometimes applied as another test on SH surfaces. ASTM D3359 standard reports the brand of tape, adhesion time and grading for the cross-cut test [33]. This method contains scoring marks 
on a target region of the coating after forming a grid of small squares before applying the adhesive tape, which is then placed at a $45^{\circ}$ angle across the grid and is removed afterwards.

Linear shear abrasion tests are also utilized. A horizontal arm holding a vertical cylinder abradant is employed that perform reciprocated motion in a linear direction. The cylinder moves across the sample surface and different grades of sandpapers, cloth, rough rubber and poly(dimethyl siloxane) films are attached to the bottom end of the cylinder as abrading materials which produce different degrees of mechanical wear on a $\mathrm{SH}$ surface. The speed, the distance of the abrading cylinder, and the pressure applied on the tested surface can be adjusted [34]. ASTM D4060 standard test can be employed using a rotary system [35]. Pencil hardness tests [36] and blade/knife tests [37] are also utilized to assess the mechanical resistance of SH surfaces.

In general, a standardized mechanical test method to characterize the abrasion resistance of the SH surfaces is lacking $[20,21,32]$ and custom built in-house systems are employed to report linear abrasion resistance results in most of the publications. Rubbing the SH samples with sandpaper [38,39], and some kind of fabrics $[38,40]$ were tried. For the standardization of the home-made abrasion tests the use of silicon carbide sandpapers with a definitive grit size seems to be reasonable. After the abrasion tests, it is better to report the water contact angle, roll-off angle and the droplet volume for a good comparison of abrasion results $[32,41]$. Water jet tests [42] and high speed scouring tests [43] were also employed. Another form of the dynamic mechanical resistance tests is to employ liquid drop solid collision or impact tests. In such tests, SH samples are generally located with a $45^{\circ}$ tilt or horizontally and micron-sized suitable particles (sand etc.) or very small water droplets are streamed down to the $\mathrm{SH}$ surface from a cup using a known height from the surface with a constant rate [38]. For such tests, no advanced equipment is used and because of the ease of experimentation many scientists preferred this method $[20,21,44]$.

On the other hand, there are problems with the correct use of "robust" or "mechanically durable" terms in the literature. Many authors reported their samples as "durable" although they did not carried out proper abrasion induced wear tests $[21,22,44,45]$. Some authors preferred to report substrate adhesion results when they employed the tape peel test without describing the applied force and the number of cycles. Such an improper tape peel test is not suitable for the use of "durable" or "robust" terms to describe the properties of a SH surface under investigation since the magnitude of applied force and the number of cycles is very important. A mechanically durable SH surface must resist the external effects by retaining its surface roughness and the surface morphology under daily life conditions.

In some cases, hydrophilic materials are used as the base plate and a thin hydrophobic layer is coated afterwards to transform such plates into a SH surface. However, when such a SH surface was rubbed with a sandpaper, the microstructures present in the top surface layers were corroded away, exposing the hydrophilic regions causing the loss of water-repellent property $[17,38]$. The use of hydrophobic materials as the base plate and imparting surface roughness with the same or another hydrophobic material is a better choice to transform such plates into a SH surface since the need for an extra hydrophobization will be eliminated. Alternatively, a hybrid composite structure may be solution. A base plate having mechanically strong microstructures carrying most of the mechanical load can be combined with nanostructures to form a SH surface for outdoor applications [7]. A real robust SH surface can be formed when some hard materials is incorporated inside a polymer matrix to improve the resistance against mechanical wear and a thin hydrophobic layer is covalently attached to the polymer matrix which can resist to chemical durability tests. Such a SH surface can also be easily applied to large areas with a suitable method. It is well known that the critical disappointment in the industrial practice is the loss of SH property after it is abraded. The use of a strong primer coating onto any base material before the application of the final top-coats having SH properties may help but only a few publications mention the use of such methods during the $\mathrm{SH}$ surface production.

In summary, many authors did not consider the outdoor robustness and mechanical resistance of the final $\mathrm{SH}$ coating in most of the published articles and thus these methods could not be successfully implemented in industrial applications. In addition, there is the lack of a standard mechanical abrasion (or durability) test method for the SH surfaces. In many articles, homemade tests such as applying linear abrasion with a sandpaper or flowing sand over a SH coating from an arbitrary ele- 
vation was employed but the downward pressure and the type of abradant used were not reported properly. Similarly, the results of pencil hardness test were reported without referencing the related ASTM method and the applied load. Then, the cross-comparisons of the values obtained from the different laboratories are not possible. In order to overcome this problem, the standardization of the abrasion tests is required by choosing the magnitude of the constant downward pressures while specific sandpapers are used and by employing the constant flow rates of specific sand grades from a specific height onto SH surfaces. Similarly, other important tests such as substrate adhesion, scratch resistance, resistance to specific chemicals should also be standardized.

\section{Contamination and Short Useful Life-Time of SH Surfaces}

The contamination of suspended particulate matter, volatile organic compounds (VOCs), smudge and surface-active substances from air in outdoor conditions hampered the long-term stability of $\mathrm{SH}$ surfaces. This issue is often overlooked, although it is a very important $[7,29]$. The contaminated layer fills the pores on the rough surface, removes the air pockets, resulting in a decrease water contact angles and corresponding increase in the surface free energy [7]. Another way of contamination on the SH surfaces is the transfer of oily substances from human fingers during daily use. Then, the contact angle hysteresis increases due to newly formed hydrophobic/hydrophilic defects. When a critical surface coverage content is reached with the contaminants, then the SH properties of the surfaces are completely lost. In some cases, natural rain has a negative effect since the pinned air layer on the $\mathrm{SH}$ surface can be removed by the impingement of the droplets of natural rain.

It is well-known that particulate matter contamination can be reduced for self-cleaning surfaces by rinsing with water droplets which can remove the dirt from the surface during rolling off [46]. Some contamination resistance tests were applied and it was reported that dirt removal is correlated to the tilt angle of the plane of the surface and to the kinetic energy of the incoming water droplets $[12,13-17,46]$. When hierarchical structures were present on a SH surface, its self-cleaning capacity was better [47].
In general, it is not possible to stop the accumulation and the removal of the contaminants by spraying water droplets from a SH surface since the long exposure to outdoor conditions causes to gradual decrease the $\mathrm{SH}$ property of surfaces by decreasing water contact angles. Some articles reported the SH property loss after they are exposed to outdoor conditions [7,17,46,48-50]. The tests of self-cleaning property on SH surfaces were not standardized since there is a lack of the systematical determination of the actual range of particles which can be removed by water rinsing [17]. The selection of the type of the polluting particulate or oily materials should be carefully done for the success of the standardized tests. In most of the published articles, only apparent contact angles were reported after the trial of the selfcleaning tests however receding contact angles are better indicators of contamination since they dramatically decrease when contaminations are present which prevent the rolling of water droplets. Thus, receding water contact angles should be reported along with apparent contact angles after the self-cleaning tests. Moreover, it is possible to study the effect of the cleaning from the particulate matter on a SH surface by the action of air (wind) by varying air pressures in a suitable laboratory.

On the other hand, the incorporation of a $\mathrm{TiO}_{2}$ layer into a SH coating formed on the glass surface was proposed to remove organic impurities deposited on this surface by the photocatalysis action since $\mathrm{TiO}_{2}$ would be activated by UV light, which transfers electrons to the conduction bands and would oxidize the impurities [48]. However, there are problems with this solution since $\mathrm{TiO}_{2}$ containing coatings are not superhydrophobic, because they convert into hydrophilic after the UV irradiation and this process cause the stain formation on the surface [51].

\section{Transparency Problems with the SH Surfaces}

Glass surfaces lose their transparency by the accumulation of dust particles when they are kept in outdoor environments and this problem is especially important for the solar panel applications in industry, where the undesirable dust films reduce the electrical production efficiency. Considerable energy and also manpower are consumed for the cleaning of the solar panels in industry. Thus, if a transparent self-cleaning SH coating can be produced which can be used on glass surfaces, then this would be very useful for solar panel applications, external windows of surveillance cameras, high building windows and automotive mirrors. 
Unfortunately, transparency and SH properties are generally incompatible due to the physical fact, that the light transmittance in a medium decreases with the increase of the surface roughness. This is the direct consequence of the Mie scattering from a rough surface, if the roughness size exceeds the wavelength of natural light $[52,53]$. Light can be reflected or absorbed on a surface and the transmissivity of light can be maximized by lowering its absorptivity and reflectivity properties Thus, the size of the roughness on a surface is important and the dimensions of the protrusions on a SH surface must be less than the wavelength of the light $(380 \mathrm{~nm}$ $\sim 760 \mathrm{~nm}$ for visible light) to give optically transparent surfaces. On the adverse side, extensive scattering of the propagated light happens due to the present roughness. In practice, the mean size of the rough particles on a SH surface should be less than $100 \mathrm{~nm}$ to obtain good transparency on this material for human eyes [52-55].

Optical interference happens when the light waves reflected by the upper and lower boundaries of a thin film and it may either enhance or reduce the reflected light. For example, when a light is reflected from oil films on water, it shows multiple colors due to thin-film interference. It is shown that, two reflected waves can strengthen each other when the film thickness is a multiple of a half of the light wavelength reducing the transmission of the light and increasing light reflection. Conversely, the reflected waves which are coming from both of the surfaces interfere and cancel each other giving complete light transmission when the thickness of the film is an odd multiple of the quarter of the light wavelength on it. An anti-reflective coating is employed on the surface of optical elements such as lenses to reduce reflection. Anti-reflectivity is the result of changing the refractive index step by step as light passes through a transparent medium. Alternating layers of contrasting refractive index are used to as ant-reflective coating to create a destructive interference to extinguish the reflected wave. However, the thickness and properties of such films are important and the objective is to obtain the situation where the incident light and the reflected light are exactly out of phase. Some type of SH surfaces were utilized as antireflective coatings [56-60]. The simplest form of an anti-reflective coating can be produced from a single transparent thin layer having a refractive index which is equal to the square root of the refractive index of the substrate. Unfortunately, no solid materials can fit such a low refractive index property, and thin films of mesoporous silica nanoparticles are generally used as antireflection coatings. Transparent surfaces with light transmittance value above $85 \%$ and having both selfcleaning property and anti-reflection ability indicate a great industrial value. Thus, the size of surface roughness should be carefully controlled to fabricate such $\mathrm{SH}$ surfaces $[20,56-60]$.

Many methods like plasma etching, chemical vapor deposition and spraying hybrid solutions were used to impart controlled roughness onto a glass or a transparent polymer surface. Transparent SH materials on windows were obtained using hybrid materials based of silica and polymers. Chemical vapor deposition, layer-by-layer, and colloidal assemblies were also utilized as bottomup approaches. Surface plasma treatment, lithographic and template-based techniques were employed as top-down methods. Solution casting using polymer/ inorganic mixtures, phase separation and electrospinning were the hybrid methods to combine the bottomup and top-down approaches [52,60]. However, a very suitable method is still lacking to coat the large area of glass or transparent polymer surfaces to form a SH surface. Most of the reported methods have poor scaleup possibilities and requires special techniques that are only suitable for laboratory scale coatings. Lithographic processes are too costly for large-scale applications because they employ templates with nano-scale roughness. The use of sol-gel methods which were applied above $400^{\circ} \mathrm{C}$ in industry seems to be difficult to manufacture the optical devices.

Moreover, the poor abrasion resistance and long-term durability of the transparent SH surfaces are important problems. No performance results were reported in most of the articles in relation with the recovering ability of the $\mathrm{SH}$ properties of the transparent surfaces against the applied abrasion induced wear $[20,21]$. The adhesion of nanoparticle films onto substrates should be improved. There are two promising approaches: the first one is the use of transparent adhesive coatings containing previously loaded nanoparticles; and the second one is the embedding of the nanoparticles into a transparent polymeric substrate by the application of thermal methods. 


\section{Inefficient Anti-Icing Applications of the SH Coatings}

It was postulated that SH surfaces can be successfully used in ice-phobic applications since they would repel the impinging water droplets and eliminate their attachment to the surface before they can freeze [61-63]. It was expected that only a minimum solid-ice interfacial contact area would be formed due to the roughness present on the SH surfaces and very small ice adhesion strength would occur after icing formation [61-66]. However, it was reported in many articles that these expectations were wrong and the use of $\mathrm{SH}$ surfaces were not successful in the anti-icing field [62,67-77].

The main reason of the negative results is the loss of $\mathrm{SH}$ properties of the coatings in temperatures below zero under high humidity. In these circumstances, the condensed water droplets nucleate and grow randomly within the hydrophobic microscale structures which are present on a SH surface [57]. Because of the existence of large surface area and the ease of confinement within the microstructures, the rate of condensation on a $\mathrm{SH}$ surface increases. Then, the growing water droplets are held in the Wenzel state on the surface and cannot be completely removed by the application of external forces $[69,78]$. When ice penetrates into a rough surface texture, then the ice adhesion strength increases. While ice formation on a SH surface occurs, this process can easily destroys the surface microstructures and harms the surface structure during the cycles of icing and deicing. Very high ice adhesion strengths were obtained in a humid atmosphere [70,71]. Moreover, delayed ice nucleation of sessile droplets occurs on these hydrophobic nanostructures $[66,68]$.

The elimination of the water droplets on a SH coating before they were frozen was not seen in sub-zero temperature experiments since the air pockets on a $\mathrm{SH}$ surface were easily removed by the impacted droplets having high velocity corresponding to a kinetic energy that allows the liquid water to imbibe into the rough structure. Afterwards, the SH property was lost on the surface and a rapid ice nucleation happened inside the rough structure. In these conditions, the large contact area of the liquid droplet with the underlying solid increased the heat transfer [63]. In summary, it was experimentally determined that the use of $\mathrm{SH}$ surfaces for the ice-phobic applications was not successful, especially in humid weather conditions [61-78]. This conclusion is dependent on the lack of the discrimination of the liquid water repellent properties of a $\mathrm{SH}$ surface from its ice repellence.

\section{Problems with the Self-Healing SH Surfaces}

When mechanical damage and fouling happens on the surfaces of some plants and insects in the nature, they can retain their water-repellent property by repairing or growing new structures on the same surface to function for a duration of their lifetime $[79,80]$. This is called as "self-healing" process and mimicking this mechanism to synthesis the artificial SH surfaces was proposed $[81,82]$. An artificial self-healing surface can regenerate its surface morphology either as a result of the external wear or with the help of another physical affect or from a chemical reaction in the surface layer. For this purpose, the imitation of the living systems by using suitable materials was suggested which can expose fresh layers on the top surface of a SH coating to heal the damages when mechanical wear or some kind of chemical erosion was applied [20,83-85].

There are some novel approaches for the utilization of artificial self-healing. It was reported that roughnessshaping components having low surface energy were embedded in polymer films, or heterogeneous interpenetrated networks, or porous matrix and they were permitted to migrate to the surface by increasing the movability of the matrix by the influence of mechanical damage, high heat etc. to restore the initial SH properties. Self-organization of hydrophobic colloidal particles at interfaces to impart roughness after mechanical wear was another option [82-88]. A silane compound was employed to make a self-healing coating, which was absorbed in the bulk coating and diffused onto the surface when any mechanical damage happens. This silane compound transformed a novel hydrophilic layer into a hydrophobic one by minimizing its surface energy and then restore the damaged layer [86].

The spraying of a mixture of fluorinated polyurethane elastomer and heptadecafluorodecyl polyhedral oligomeric silsesquioxane was used to prepare an artificial self-healing $\mathrm{SH}$ surface. This coating could return into its initial water repellent properties after mechanically 
eroded, sonicated, burned or chemically attacked [87]. In another study, a suspension containing $\mathrm{TiO}_{2}$ nanoparticles in an aluminum phosphate binder and alkylsilane was sprayed onto substrates to fabricate $\mathrm{SH}$ surfaces which was self-healing and resistant to hot oil, water, and acetone [88].

However, there are drawbacks with the production of self-healing SH surfaces. The most important difficulty is the necessity that both of the surface hydrophobicity and roughness should be regenerated simultaneously. For this purpose, low molecular weight hydrophobic components should rapidly migrate towards the damaged surface from the matrix polymer in order to regenerate the surface hydrophobicity. But, this is not an easy process since the bulk system should be soft and has a high degree of mobility for this purpose. Contrary to previous expectations, the surface free energy differences between the matrix and the migrating low energy chemical is not enough for this process. Besides, if the matrix has such a high degree of mobility, then it cannot regenerate the surface roughness rapidly. Thus, the process of simultaneous and spontaneous regeneration of the topographic structures is very difficult.

In order to carry out the regeneration of the surface roughness on self-healing SH surfaces, some hard particles were used in the polymer matrix and it was expected that when the surface was mechanically harmed then these roughness-shaping particles could reach to the top of the surface to generate new roughness profiles, or to mimic the initial surface roughness. Unfortunately, this step is very difficult and the experiments carried out so far were not very successful. When some external effects were applied to initiate the healing process such as temperature, moisture, light, or a $\mathrm{pH}$ switch, these stimuli may be successful but they usually do not match to the situations in daily life at normal conditions. Another problem is the lack of standard procedures to characterize the success of the self-healing SH materials and coatings. On the other hand, many low surface tension chemicals, which were used in the self-healing $\mathrm{SH}$ research were expensive, toxic and sometimes can evaporate or drain away during the daily conditions. It seems that the self-healing SH surface research may be promising if the regeneration of both of the hydrophobicity of the top layer of the coating and initial roughness levels can be successfully carried out.

\section{CONCLUSIONS and OUTLOOK}

The size of the industrial production of the SH coatings and materials is inadequate when compared with the intensive research output as expressed in the number of published articles in this field (more than 14.000) for the last two decades by the participation of many high level universities, national laboratories, and research centers. In this review article, we discussed the reasons for this adverse situation under several topics. The most important problems are the insufficient mechanical resistance and inevitable contamination of the SH surfaces under outdoor conditions, resulting in short useful life-times. In most of the publications, spray coating of composite inorganic/polymer solutions was proposed without meeting the main requirements for the mechanical resistance of the matrix polymers, which would support the top layers. The powerful bonding of inorganic particles to the polymer matrix and strong adhesion of the matrix polymer layer to the target substrate are two significant requirements for practical applications of $\mathrm{SH}$ materials. It is not possible to employ such $\mathrm{SH}$ coatings without meeting the required standards which are common in the surface coatings industry. It should be noted that no micro crack formation is allowed for any $\mathrm{SH}$ surface after drying. In addition, the control of the height of the particles over the flat surface indicates the surface roughness degree and this is an important issue. On the other hand, only the production of two different size scale roughness on a surface is adequate and there is no need to use fluorine containing harmful and expensive materials to synthesize the $\mathrm{SH}$ surfaces. The use of cheap and suitably functional polymeric or inorganic transparent primers or inter-adhesive layers between the target substrate and the top-coat layer which has $\mathrm{SH}$ properties may be a good solution for the industrial production. The research on the SH surfaces can be directed toward large-scale production methods using low cost and environmental friendly raw materials. For the transparent SH surfaces, the use of transparent primer adhesive layers containing nanoparticles or embedding the nanoparticles into a transparent polymeric substrate by applying moderate thermal methods are two promising approaches. In summary, the probability of the widespread applications of the SH surfaces in industry is low at present, but this may change in the not so distant future. 


\section{References}

1. H.Y. Erbil, Surface Chemistry of Solid and Liquid Interfaces, Blackwell Publishing, Oxford, UK, 2006

2. H.J. Butt, K. Graf, M. Kappl, Physics and Chemistry of Interfaces, Wiley-VCH, Weinheim, Germany, 2003.

3. E.Y. Bormashenko, Wetting of Real Surfaces, De Gruyter, Berlin, Germany, 2013.

4. H.Y. Erbil, The debate on the dependence of apparent contact angles on drop contact area or 3-phase contact line: A review, Surf. Sci. Rep., 69 (2014) 325-365.

5. P. Roach, N.J. Shirtcliffe, M.I. Newton, Progress in superhydrophobic surface development, Soft Matter, 4 (2008) 224-240.

6. H.Y. Erbil, A.L. Demirel, Y. Avci, O. Mert, Transformation of a simple plastic into a superhydrophobic surface, Science, 299 (2003) 1377-1380.

7. C. Dorrer, J. Ruhe, Some thoughts on superhydrophobic wetting, Soft Matter, 5 (2009) 51-61.

8. W. Barthlott, C. Neinhuis, Purity of the sacred lotus, or escape from contamination in biological surfaces, Planta, 202 (1997) 1-8.

9. R. Furstner, W. Barthlott, C. Neinhuis, P. Walzel, Wetting and self-cleaning properties of artificial superhydrophobic surfaces, Langmuir, 21 (2005) 956-961.

10. A.R. Parker, C.R. Lawrence, Water capture by a desert beetle, Nature, 414 (2001) 33-34

11. X. Gao, L. Jiang, Water-repellent legs of water striders, Nature, 432 (2004) 36

12. Q. Cong, G.H. Chen, Y. Fang, L.Q. Ren, Study on the superhydrophobic characteristic of butterfly wing surface, J. Bionic Eng., 1 (2004) 249-252.

13. T. Sun, L. Feng, X. Gao, L. Jiang, Bioinspired surfaces with special wettability, Acc. Chem. Res., 38 (2005) 644-652.

14. X. Li, D. Reinhoudt, M. Crego-Calama, What do we need for a superhydrophobic surface? A review on the recent progress in the preparation of superhydrophobic surfaces, Chem. Soc. Rev., 36 (2007) 1350-1368.

15. M. Nosonovsky, B. Bhushan, Superhydrophobic surfaces and emerging applications: Non-adhesion, energy, green engineering, Cur. Opin. Colloid Interface Sci., 14 (2009) 270 280.

16. B. Bhushan, Y.C. Jung, Natural and biomimetic artificial surfaces for superhydrophobicity, self-cleaning, low adhesion, and drag reduction, Prog. Mater. Sci., 56 (2011) 1-108.

17. T. Verho, C. Bower, P. Andrew, S. Franssila, O. Ikkala, R.H. Ras, Mechanically durable superhydrophobic surfaces, Adv. Mater., 23 (2011) 673-678.

18. C.H. Xue, S.T. Jia, J. Zhang, J.Z. Ma, Large-area fabrication of superhydrophobic surfaces for practical applications: an overview, Sci. Technol. Adv. Mater., 11 (2010) 033002.

19. L. Wen, Y. Tian, L. Jiang, Bioinspired super-wettability from fundamental research to practical applications, Angew. Chem. Int. Ed., 54 (2015) 3387-3399.

20. I.S. Bayer, On the durability and wear resistance of transparent superhydrophobic coatings, Coatings, 7 (2017) 12.

21. K. Ellinas, A. Tserepi, E. Gogolides, Durable superhydrophobic and superamphiphobic polymeric surfaces and their applications: A review, Adv. Colloid Interface Sci., 250 (2017) 132-157.
22. J. Jeevahan, M. Chandrasekaran, B.G. Joseph, R.B. Durairaj, G. Mageshwaran, Superhydrophobic surfaces: A review on fundamentals, applications, and challenges, J. Coat. Technol. Res., 15 (2018) 231-250.

23. P. Nguyen-Tri, H.N. Tran, C.O. Plamondon, L. Tuduri, D.V.N. Vo, S. Nanda, A. Mishra, H.P. Chao, A.K. Bajpai, Recent progress in the preparation, properties and applications of superhydrophobic nano-based coatings and surfaces: A review, Prog. Org. Coat., 132 (2019) 235-256.

24. T. Kong, G. Luo, Y. Zhao, Z. Liu, Bioinspired superwettability micro/nanoarchitectures: fabrications and applications, Adv. Funct. Mater., 29 (2019) 1808012.

25. H.Y. Erbil, Practical applications of superhydrophobic materials and coatings: problems and perspectives, Langmuir, 36 (2020) 2493-2509.

26. G. McHale, D.L. Herbertson, S.J. Elliott, N.J. Shirtcliffe, M.I. Newton, Electrowetting of nonwetting liquids and liquid marbles, Langmuir, 23 (2007) 918-924.

27. S.H. Anastasiadis, Development of functional polymer surfaces with controlled wettability, Langmuir, 29 (2013) 9277-9290.

28. H.Y. Erbil, B. Hazer, Surface-free energy analysis of polystyrenepoly(ß- hydroxynonanoate) graft copolymers, J. App. Polym. Sci., 60 (1996) 1313-1320.

29. Nakajima, K. Abe, K. Hashimoto, T. Watanabe, Preparation of hard super-hydrophobic films with visible light transmission, Thin Solid Films, 376 (2000) 140-143.

30. C.E. Cansoy, H.Y. Erbil, O. Akar, T. Akin, Effect of pattern size and geometry on the use of Cassie-Baxter equation for superhydrophobic surfaces, Colloids Surf., A, 386 (2011) 116-124.

31. Solga, Z. Cerman, B.F. Striffler, M. Spaeth, W. Barthlott, The dream of staying clean: Lotus and biomimetic surfaces, Bioinspiration Biomimetics, 2 (2007) 126-S134.

32. X. Tian, T. Verho, R.H.A. Ras, Moving superhydrophobic surfaces toward real-world applications, Science, 352 (2016) 6282, 142-143

33. D3359-09, Standard Test Methods for Measuring Adhesion by Tape Test. 2013, ASTM 1-7.

34. Steele, B.K. Nayak, A. Davis, M.C. Gupta, E. Loth, Linear abrasion of a titanium superhydrophobic surface prepared by ultrafast laser microtexturing, J. Micromech. Microeng., 23 (2013) 1-8.

35. D4060-D968, Standard Test Methods for Abrasion Resistance of Organic Coatings by Falling Abrasive. 2005, ASTM Annu. Stand. 05 5-9.

36. M. Paven, R. Fuchs, T. Yakabe, D. Vollmer, M. Kappl, A.N. Itakura, H.J. Butt, Mechanical properties of highly porous super liquid-repellent surfaces, Adv. Funct. Mater., 26 (2016) 4914-4922.

37. H. Wang, H. Zhou, A. Gestos, J. Fang, T. Lin, Robust, Superamphiphobic fabric with multiple self-healing ability against both physical and chemical damages, ACS Appl. Mater. Interfaces, 5 (2013) 10221-10226.

38. Y. Xiu, Y. Liu, D.W. Hess, C.P. Wong, Mechanically robust superhydrophobicity on hierarchically structured Si surfaces, Nanotechnology, 21 (2010) 155705.

39. I.S. Bayer, A. Brown, A. Steele, E. Loth, Transforming anaerobic adhesives into highly durable and abrasion resistant superhydrophobic organoclay nanocomposite films: A new hybrid spray adhesive for tough superhydrophobicity, Appl. Phys. Express, 2 (2009) 125003. 
40. T. Yanagisawa, A. Nakajima, M. Sakai, Y. Kameshima, K Okada, Preparation and abrasion resistance of transparent super-hydrophobic coating by combining crater-like silica films with acicular boehmite powder, Mater. Sci. Eng., B, 161 (2009) 36-39.

41. J. Bico, C. Marzolin, D. Quere, Pearl drops, Europhys. Lett., 47 (1999) 220-226.

42. Y. Jung, B. Bhushan, Mechanically durable carbon nanotubecomposite hierarchical structures with superhydrophobicity, self-cleaning, and low-drag, ACS Nano, 3 (2009) 4155-4163.

43. Z. Cui, Q. Wang, Y. Xiao, C. Su, Q. Chen, Q. The stability of superhydrophobic surfaces tested by high speed current scouring, Appl. Surf. Sci., 254 (2008) 2911-2916.

44. V. Mortazavi, M.M. Khonsari, On the degradation of superhydrophobic surfaces: A review, Wear, 372-373 (2017) 145-157.

45. R.J.L. Scarratt, U. Steiner, C. Netoa, A review on the mechanical and thermodynamic robustness of superhydrophobic surfaces, Adv. Colloids Interface Sci., 246 (2017) 133-152.

46. C. Neinhuis, W. Barthlott, Characterization and distribution of water-repellent, self-cleaning plant surfaces, Annal. Botany 79 (1997) 667-677

47. U. Cengiz, H.Y. Erbil, Superhydrophobic perfluoropolymer surfaces having heterogeneous roughness created by dipcoating from solutions containing a non-solvent, Appl. Surf. Sci., 292 (2014) 591-597.

48. Nakajima, K. Hashimoto, T. Watanabe, K. Takai, G. Yamauchi, A. Fujishima, Transparent superhydrophobic thin films with self-cleaning properties, Langmuir, 16 (2000) 7044-7047.

49. Bhushan, Y. Jung, K. Koch, Self-cleaning efficiency of artificial superhydrophobic surfaces, Langmuir, 25 (2009) 3240-3248.

50. N. Yoshida, M. Takeuchi, T. Okura, H. Monma, M. Wakamura, H. Ohsaki, T. Watanabe, Super-hydrophobic photocatalytic coatings utilizing apatite-based photocatalyst, Thin Solid Films, 502 (2006) 108-111.

51. K. Tadanaga, J. Morinaga, A. Matsuda, T. Minami, Superhydrophobic-superhydrophilic micropatterning on flowerlike alumina coating film by the sol-gel method Chem. Mater., 12 (2000) 590-592.

52. G. Mie, Beitrage zur optik truber medien, speziell kolloidaler metallosungen, Ann. Phys., 25 (1908) 377-388.

53. Nakajima, A. Fujishima, K. Hashimoto, T. Watanabe, T. Preparation of transparent superhydrophobic boehmite and silica films by sublimation of aluminum acetylacetonate, Adv. Mater., 11 (1999) 1365-1368.

54. H. Yabu, M. Shimomura, Single-step fabrication of transparent superhydrophobic porous polymer films, Chem Mater., 17 (2005) 5231-5234.

55. Y. Li, J. Zhang, S. Zhu, H. Dong, F. Jia, Z. Wang, Z. Sun, L. Zhang, Y. Li, H. Li, W. Xu, B. Yang, Biomimetic surfaces for high-performance optics, Adv. Mater., 21 (2009) 4731-4734.

56. Y. Xiu, S. Zhang, V. Yelundur, A. Rohatgi, D.W. Hess, C.P. Wong Superhydrophobic and low light reflectivity silicon surfaces fabricated by hierarchical etching, Langmuir, 24 (2008) 10421-10426

57. S. Guldin, P. Kohn, M. Stefik, J. Song, G. Divitini, F. Ecarla, C. Ducati, U. Wiesner, U. Steiner, Self-cleaning antireflective optical coatings, Nano Lett., 13 (2013) 5329-5335.

58. L. Yao, J. He, Recent progress in antireflection and selfcleaning technology - From surface engineering to functional surfaces, Prog. Mater. Sci., 61 (2014) 94-143.
59. E. Kasapgil, E.G. Atici, R. Çiçek, I. Anaç, H.Y. Erbil, Superhydrophobic polysiloxane filament growth on nonactivated polymer coatings, RSC Adv., 6 (2016) 74921-74928.

60. E. Kasapgil, I. Anaç, H.Y. Erbil, Transparent, fluorine-free, heat-resistant, water repellent coating by infusing slippery silicone oil on polysiloxane nanofilament layers prepared by gas phase reaction of $n$-propyltrichlorosilane and methyltrichlorosilane, Colloids Surf., A, 560 (2019) 223-232.

61. J. LV, Y. Song, L. Jiang, J. Wang, Bio-inspired strategies for anti-icing, ACS Nano, 8 (2014) 3152-3169.

62. T.M. Schutzius, S. Jung, T. Maitra, P. Eberle, C. Antonini, C. Stamatopoulos, D. Poulikakos, Physics of icing and rational design of surfaces with extraordinary icephobicity, Langmuir, 31 (2015) 4807-4821.

63. M.J. Kreder, J. Alvarenga, P. Kim, J. Aizenberg, Design of anti-icing surfaces: smooth, textured or slippery?, Nat. Rev. Mater., 1 (2016) 15003.

64. L. Cao, A.K. Jones, V.K. Sikka, J. Wu, D. Gao, Anti-icing superhydrophobic coatings, Langmuir, 25 (2009) 1244412448.

65. M. He, J. Wang, H. Li, Y. Song, Superhydrophobic surfaces to condensed micro-droplets at temperatures below the freezing point retard ice/frost formation, Soft Matter, 7 (2011) 3993-4000.

66. P. Guo, Y. Zheng, M. Wen, C. Song, Y. Lin, L. Jiang, Icephobic/ anti-icing properties of micro/nanostructured surfaces, Adv. Mater., 24 (2012) 2642-2648.

67. A.J. Meuler, G.H. McKinley, R.E. Cohen, Exploiting topographical texture to impart icephobicity, ACS Nano, 4 (2010) 7048-7052.

68. S. Jung, M. Dorrestijn, D. Raps, A. Das, C.M. Megaridis, D. Poulikakos, Are superhydrophobic surfaces best for icephobicity?, Langmuir, 27 (2011) 3059-3066.

69. K.K. Varanasi, T. Deng, J.D. Smith, M. Hsu, N. Bhate, Frost formation and ice adhesion on superhydrophobic surfaces, Appl. Phys. Lett., 97 (2010) 234102.

70. S. Farhadi, M. Farzaneh, S.A. Kulinich, Anti-icing performance of superhydrophobic surfaces, Appl. Surf. Sci., 257 (2011) 6264-6269.

71. S.A. Kulinich, S. Farhadi, K. Nose, X.W. Du, Superhydrophobic surfaces: Are they really ice-repellent?, Langmuir, 27 (2011) 25-29.

72. J. Chen, J. Liu, M. He, K. Li, D. Cui, Q. Zhang, X. Zeng, Y. Zhang, J. Wang, Y. Song, Superhydrophobic surfaces cannot reduce ice adhesion, Appl. Phys. Lett., 101 (2012) 111603.

73. M. Nosonovsky, V. Hejazi, Why superhydrophobic surfaces are not always icephobic, ACS Nano, 6 (2012) 8488-8491.

74. L. Oberli, D. Caruso, C. Hall, M. Fabretto, P.J. Murphy, D. Evans, Condensation and freezing of droplets on superhydrophobic surfaces, Adv. Colloid Interface Sci., 210 (2014) 47-57.

75. S. Özbay, C. Yuceel, H.Y. Erbil, Improved icephobic properties on surfaces with a hydrophilic self-lubricating liquid, ACS Appl. Mater. Interfaces, 7 (2015) 22067-22077.

76. S. Özbay, H.Y. Erbil, Ice accretion by spraying supercooled droplets is not dependent on wettability and surface free energy of substrates, Colloids Surf., A, 504 (2016) 210-218.

77. Y. Lin, H. Chen, G. Wang, A. Liu, Recent progress in preparation and anti-icing applications of superhydrophobic coatings, Coatings, 8 (2018) 208.

78. R.D. Narhe, D.A. Beysens, Nucleation and growth on a superhydrophobic grooved surface, Phys. Rev. Lett., 93 (2004) 076103 
79. K. Koch, B. Bhushan, H.J. Ensikat, W. Barthlott, Self-healing of voids in the wax coating on plant surfaces, Philos. Trans. R. Soc. London, Ser. A, 367 (2009) 1673-1688.

80. D. Shchukin, H. Möhwald, Self-repairing coatings containing active nanoreservoirs, Small, 3 (2007) 926-943.

81. J.P. Youngblood, N.R. Sottos, C. Extrand, Bioinspired materials for self-cleaning and self-healing, MRS Bull., 33 (2008) 732-738.

82. M. Nosonovsky, B. Bhushan, Surface self-organization: from wear to self-healing in biological and technical surfaces, Appl. Surf. Sci., 256 (2010) 3982-3987.

83. R.P. Wool, Self-healing materials: A review, Soft Matter, 4 (2008) 400-418.
84. Das, J. Deka, K. Raidongia, U. Manna, Robust and selfhealable bulk-superhydro-phobic polymeric coating, Chem. Mater., 29 (2017) 8720-8728.

85. Esteves, Self-healing functional surfaces, Adv. Mater. Interfaces, 5 (2018) 1800293

86. Y. Li, L. Li, J. Sun, Bioinspired self-healing superhydrophobic coatings, Angew. Chem. Int. Ed., 49 (2010) 6129-6133.

87. K. Golovin, M. Boban, J.M. Mabry, A. Tuteja, Designing self-healing superhydrophobic surfaces with exceptional mechanical durability, ACS Appl. Mater. Interfaces, 9 (2017) 11212-11223.

88. M. Liu, Y. Hou, J. Li, L. Tie, Y. Peng, Z. Guo, Inorganic adhesives for robust, self-healing, superhydrophobic surfaces, J. Mater. Chem. A, 5 (2017) 19297-19305. 